\title{
Sedation in Gastrointestinal Endoscopy: An Anesthesiologist's Perspective
}

\author{
Philippe Van der Linden \\ Department of Anesthesiology, CHU Brugmann - HUDERF, Free University of Brussels, Brussels, Belgium
}

\section{Key Words}

Sedation · Analgesia • Non-anesthesiologists

\begin{abstract}
Sedation is required to treat an ever increasing number of patients for medical diagnostic or therapeutic procedures, in particular in gastrointestinal endoscopy. Due to the apparent ease of administration of sedative techniques, and due to the shortage of anesthetic staff in many Western countries, sedation is being carried out more and more frequently by non-anesthesiologist doctors or even paramedical staff. Due to its pharmacokinetic properties, propofol has become the preferred sedative drug used by non-anesthesiologists. However, uncritical use of propofol by nonqualified persons might result in much higher complications rates and even fatal events. Several guidelines have been published with common issues, but also some significant differences. Whether they contribute to improved patient safety or not will depend on the practical application and interpretation of these guidelines. Although further evaluation is needed, computer-assisted systems might contribute to the safe administration of propofol through a better control of the level of sedation.

Copyright $\odot 2010$ S. Karger AG, Basel
\end{abstract}

(c) 2010 S. Karger AG, Basel

$0012-2823 / 10 / 0822-0102 \$ 26.00 / 0$

Fax +4161306 1234

E-Mail karger@karger.ch

www.karger.com
Accessible online at: www.karger.com/dig

\section{Introduction}

The provision of sedation and analgesia has been an important component of performing endoscopic procedures on the gastrointestinal tract. The different procedures can create pain and discomfort and are often associated with anxiety for the patient. Of course, comfort is important, but patient cooperation, either active or passive, is also critical to the success of the examination. McQuaid and Laine [1] performed a systematic review of randomized controlled trials of moderate sedation for routine esogastroduodenoscopy or colonoscopy in adult patients. They observed that moderate sedation provides a high level of physician and patient satisfaction, and a low risk of serious adverse events with all currently available agents. Because anesthesiologists possess specific expertise in the pharmacology, physiology and clinical management of patients receiving sedation and analgesia, they have become involved in the care of many patients undergoing endoscopic procedures [2]. However, in the current environment, things are changing. The demand for endoscopy, especially screening colonoscopies, has increased dramatically. More stimulating and complex procedures that can be accomplished with the endoscope are emerging. New medications for sedation and analgesia are either under investigation or already avail-

Philippe Van der Linden, MD, PhD, Department of Anesthesiology

CHU Brugmann - HUDERF, Free University of Brussels

4 Place Van Gehuchten, BE-1020 Brussels (Belgium)

Tel. +32 2477 3996, Fax +32 24773345

E-Mail philippe.vanderlinden@chu-brugmann.be 
able on the market. Standards for monitoring and discharge criteria are improving. Due to the shortage in human resources, anesthesiologists cannot provide services for all requested procedures. Moreover, reimbursement for sedation services provided by anesthesiologists implies a substantial increase in healthcare costs, which is challenged by healthcare insurance companies in some countries [3]. The role of anesthesiologists in the field of endoscopic procedures must evolve. On the one hand, they have to participate in the care of the more fragile patients or those undergoing the most complex procedures. On the other hand, they have to collaborate in the formulation of sedation and/or analgesia guidelines for nonanesthetic medical personnel with adequate minimum guarantees for safety and quality of care [4].

\section{The Risks Associated with Sedation and/or Analgesia}

Due to its unique pharmacokinetic properties, propofol has become the preferred sedative drug used by nonanesthesiologists. Along with its increased use, controversies over how to use it safely and efficiently and over who should administer this agent have arisen. Rex et al. [5] recently reviewed all published work on endoscopistdirected propofol sedation. On the basis of more than 200,000 cases, they claimed endoscopist-directed propofol sedation had an excellent safety profile with only 213 patients needing temporary mask ventilation, but not intubation, no death and no neurological damage.

However, the authors completely ignored other safety end-points reported, even in publications they referred to. For example, Kulling et al. [6] reported a fall of the oxygen saturation in $2.3 \%$ of the 27,000 patients $(5.5 \%$ in patients aged $>70$ years), although $21 /$ min oxygen was administered systematically to the patients. Because ECG and noninvasive blood pressure monitoring was used in only a few patients, no statement on hemodynamic stability could be made. In addition, as no ventilation monitoring was used, no statement could be made about hypoventilation episodes resulting in significant hypercapnia. It is well known that supplemental oxygen can mask hypoventilation when only peripheral oxygen saturation is monitored [7].

Uncritical use of propofol or other sedation agents by unqualified persons may be responsible for increased complication rates. Currently, the incidence of morbidity and mortality during a hospital-based anesthetic is approximately $1 / 400,000$ [8]. Thus, to accurately estimate

Sedation in Gastrointestinal Endoscopy if the safety in non-anesthetist sedation procedures is equivalent, one would need a very large sample size, which was not the case of the Rex et al. [5] study. In addition, mortality-related to anesthesia also depends on the age and the physical status of the patient. In a recent epidemiologic study, Lienhart et al. [9] clearly showed that mortality related to anesthesia increases by a factor of 100 in patients with an ASA status of III or higher in comparison to patients with an ASA status of I or II. Incidence of sedation-related cardiopulmonary complications also correlated with ASA status as shown by Vargo et al. [10] in patients undergoing upper endoscopy.

In this study, monitored anesthesia care was associated with a significantly lower relative risk. In advanced endoscopic procedures, Coté et al. [11] reported that male sex, ASA status III or higher and increased body mass index are independent predictors of sedation-related adverse events. Another factor to take into account is the level of sedation: the higher the level, the higher the risk of hemodynamic and/or respiratory complications. It is therefore critical to publish guidelines defining as precisely as possible the conditions for sedation administration by non-anesthesiologists.

\section{Anesthesiologist- versus Gastroenterologist-Driven Guidelines}

Several guidelines for gastroenterologist-directed propofol use and training have been published recently [12, 13]. Whereas the German guidelines have been written in collaboration with representatives of the German Society for Anesthesiology and Intensive Care [13], the US guidelines were released without involvement of anesthesiologists [12]. When compared with the guidelines published by the American Society of Anesthesiologists (ASA) in 2002 [2] and reviewed in 2004 and 2006, several issues common to all three guidelines can be seen: the definition of the different levels of sedation; the need for a structured pre-procedure patient evaluation including informed consent; the use of a specific monitoring for sedation; the clinical assessment of the depth of sedation; the presence of one individual dedicated to patient monitoring, trained in advanced life support skills including bag-valve-mask ventilation, defibrillation and use of resuscitation drugs; and the need for special training of non-anesthesiologist physicians and nurses in advanced life support and pharmacology [14].

However, in contrast to the German and the ASA guidelines, the US guidelines remained ambiguous with 
respect to the administration of sedation in ASA III-IV patients. Lichtenstein et al. [12] stated that the benefit of involving anesthesiologists in ASA IV or higher patients and in patients with a difficult airway or history of inadequate response to sedation is unclear. This statement contrasts with the literature $[10,11]$ and puts high-risk patients at a potentially fatal risk. Sedation of such patients by non-anesthesiologists cannot be justified.

The contribution of these different guidelines $[2,12$, 13] and others [4] to improved patient safety will clearly depend on their practical application and interpretation.

\section{Future Developments to Improve Patient Safety during Sedation for Endoscopic Procedures}

In order to avoid over-sedation, patient-controlled sedation has been evaluated [15] and its safety profile was found to be excellent. However, as the patients react only to an unpleasant event by starting a propofol bolus, the desired sedation effect was mostly delayed with respect to the clinical stimulation. This results in insufficient sedation and/or an analgesia level with decreased patient satisfaction.

Two computer-assisted sedation systems are currently being developed to improve patient safety during sedation for endoscopic procedures while maintaining a high satisfaction level [14]. The developed systems evaluate the sedation state of the patient and automatically adjust dosing accordingly.

The first system combines standard monitoring with an automatic responsiveness monitor based on computerized tactile and verbal stimulation of the patient. The monitoring is combined with oxygen and drug delivery units. The drug delivery unit for propofol basically mim- ics the dosing profile of a target-controlled infusion pump. In a very preliminary study, the device appeared to perform well with no device-related adverse event [16].

The second system relies on the readily measurable respiratory depression via transcutaneous carbon dioxide measurements combined with respiratory rate monitoring. The drug infusion is then controlled to reach and maintain a predefined carbon dioxide level, thereby providing an individualized sedation level while avoiding over-sedation. This system is currently under clinical investigation [17].

Studies in the future will indicate if these computerassisted systems may help to prevent over-sedation by non-anesthesiologists and anesthesiologists during endoscopic procedure. Whatever their efficacy, they will never replace the person dedicated for patient monitoring, a person trained in advanced life support skills including bag-valve-mask ventilation, defibrillation and use of resuscitation drugs. At best, these systems can help to control the sedation level.

\section{Conclusions}

Propofol use by non-anesthesiologists will increase in the future due to the increased number of endoscopies and to increased demand by patients. The development of well-defined guidelines through close collaboration between gastroenterologists and anesthesiologists will improve the safety of sedation administration to patients undergoing endoscopic procedures, if adequately applied. In the future, computer-assisted systems for propofol administration might be useful for controlling the level of sedation.

\section{References}

1 McQuaid KR, Laine L: A systematic review and meta-analysis of randomized, controlled trials of moderate sedation for routine endoscopic procedures. Gastrointest Endosc 2008;67:910-923.

-2 American Society of Anesthesiologists Task Force on Sedation and Analgesia by NonAnesthesiologists: Practice guidelines for sedation and analgesia by non-anesthesiologists. Anesthesiology 2002;96:1004-1017.

$\checkmark 3$ Aisenberg J, Brill JV, Ladabaum U, Cohen LB: Sedation for gastrointestinal endoscopy: new practices, new economics. Am J Gastroenterol 2005;100:996-1000. $\checkmark 4$ Knape JT, Adriaensen H, van Aken H, Blunnie WP, Carlsson C, Dupont M, Pasch T: Guidelines for sedation and/or analgesia by non-anaesthesiology doctors. Eur J Anaesthesiol 2007;24:563-567.

$\checkmark 5$ Rex DK, Deenadayalu VP, Eid E, Imperiale TF, Walker JA, Sandhu K, Clarke AC, Hillman LC, Horiuchi A, Cohen LB, Heuss LT, Peter S, Beglinger C, Sinnott JA, Welton T, Rofail M, Subei I, Sleven R, Jordan P, Goff J, Gerstenberger PD, Munnings H, Tagle M, Sipe BW, Wehrmann T, Di Palma JA, Occhipinti KE, Barbi E, Riphaus A, Amann ST, Tohda G, McClellan T, Thueson C, Morse J,
Meah N: Endoscopist-directed administration of propofol: a worldwide safety experience. Gastroenterology 2009;137:1229-1237, quiz 1518-1519.

6 Kulling D, Orlandi M, Inauen W: Propofol sedation during endoscopic procedures: how much staff and monitoring are necessary? Gastrointest Endosc 2007;66:443449.

7 Fu ES, Downs JB, Schweiger JW, Miguel RV, Smith RA: Supplemental oxygen impairs detection of hypoventilation by pulse oximetry. Chest 2004;126:1552-1558. 
8 Hausman LM, Reich DL: Providing safe sedation/analgesia: an anesthesiologist's perspective. Gastrointest Endosc Clin N Am 2008;18:707-716, viii.

-9 Lienhart A, Auroy Y, Pequignot F, Benhamou D, Warszawski J, Bovet M, Jougla E: Survey of anesthesia-related mortality in France. Anesthesiology 2006;105:1087-1097.

-10 Vargo JJ, Holub JL, Faigel DO, Lieberman DA, Eisen GM: Risk factors for cardiopulmonary events during propofol-mediated upper endoscopy and colonoscopy. Aliment Pharmacol Ther 2006;24:955-963.

- 11 Coté GA, Hovis RM, Ansstas MA, Waldbaum L, Azar RR, Early DS, Edmundowicz SA, Mullady DK, Jonnalagadda SS: Incidence of sedation-related complications with propofol use during advanced endoscopic procedures. Clin Gastroenterol Hepatol 2010;8:137-142.
12 Lichtenstein DR, Jagannath S, Baron TH, Anderson MA, Banerjee S, Dominitz JA, Fanelli RD, Gan SI, Harrison ME, Ikenberry SO, Shen B, Stewart L, Khan K, Vargo JJ: Sedation and anesthesia in GI endoscopy. Gastrointest Endosc 2008;68:815-826.

13 Riphaus A, Wehrmann T, Weber B, Arnold J, Beilenhoff U, Bitter H, von Delius S, Domagk D, Ehlers AF, Faiss S, Hartmann D, Heinrichs W, Hermans ML, Hofmann C, In der Smitten S, Jung M, Kahler G, Kraus M, Martin J, Meining A, Radke J, Rosch T, Seifert H, Sieg A, Wigginghaus B, Kopp I: S3-guidelines - sedation in gastrointestinal endoscopy (in German). Z Gastroenterol 2008;46: $1298-1330$
4 Luginbuhl M, Vuilleumier P, Schumacher P, Stuber F: Anesthesia or sedation for gastroenterologic endoscopies. Curr Opin Anaesthesiol 2009;22:524-531.

15 Heuss LT, Peter S: Propofol use by gastroenterologists - the European experience. Gastrointest Endosc Clin N Am 2008;18:727738, ix.

16 Pambianco DJ, Whitten CJ, Moerman A, Struys MM, Martin JF: An assessment of computer-assisted personalized sedation: a sedation delivery system to administer propofol for gastrointestinal endoscopy. Gastrointest Endosc 2008;68:542-547.

17 Caruso AL, Bouillon TW, Schumacher PM, Morari M: On the modeling of drug induced respiratory depression in the non-steadystate. Conf Proc IEEE Eng Med Biol Soc 2008;2008:5564-5568. 